\title{
Screening of Advanced Breeding Material of Sorghum against Shoot Fly (Atherigona soccata) (Rondani)
}

\author{
S.P. Patil* and A.S. Bagde \\ Department of Agri. Entomology, College of Agriculture, \\ Kolhapur - 416 004, Maharashtra, India \\ *Corresponding author
}

\begin{tabular}{|c|c|}
\hline & A B S T RA C T \\
\hline $\begin{array}{l}\text { Sorghum, } \\
\text { Atherigona soccata. }\end{array}$ & \multirow{3}{*}{$\begin{array}{l}\text { The present investigation of screening of eleven advanced breeding lines of } \\
\text { sorghum along with three replications against shoot fly was carried out in } \\
\text { randomized block design (RBD) at Agronomy field, college of agriculture } \\
\text { Kolhapur in Rabi } 2016-17 \text {. The advanced breeding breeding lines were } \\
\text { screened on the basis of average number of eggs laid and percent dead } \\
\text { hearts per plant at } 14,21 \text { and } 28 \text { days after emergence. Resistant checks } \\
\text { viz., IS } 2312 \text {, IS } 2215 \text { and IS } 18551 \text { recorded significantly minimum } \\
\text { number of eggs per plant and also exhibited minimum average percentage } \\
\text { of dead hearts. }\end{array}$} \\
\hline Article Info & \\
\hline $\begin{array}{l}\text { Accepted: } \\
26 \text { August } 2017 \\
\text { Available Online: } \\
\text { 10 September } 2017\end{array}$ & \\
\hline
\end{tabular}

\section{Introduction}

Sorghum [Sorghum bicolor (L.) Monech] is the fifth most important cereal crop worldwide after wheat, rice, maize and barley (FAO, 2011). In Maharashtra, sorghum is being grown on 5.50 million hectares and production is 6.05 million tonnes. sorghum shoot fly, Atherigona soccata Rondani (Order- Diptera, Family- Muscidae) is the most destructive one and causes severe damage in the early i.e. seedling stage and last up to 4 weeks causing severe reduction in plant population thereby causing heavy yield losses. The maggot crawls to the plant whorl and then moves downward between the fold of young leaves till they reach the growing point. It cuts the growing tip and feeds on the decaying leaf tissues, which results in dead heart formation.
Resistance to shoot fly, A. soccata in sorghum is expressed in terms of antixenosis for ovipositon, antibiosis and tolerance (Sharma and Nwanze, 1997; Dhillon et al., 2005 a, b).

\section{Materials and Methods}

Screening of eleven advanced breeding lines of sorghum along with three replications against shoot fly was carried out in randomized block design (RBD) at Agronomy field, college of agriculture Kolhapur in Rabi 2016-17. genotypes comprising IS 29923, IS 18360, IS 27204, RSSH 18, RSSH 50, Swarna, three resistant checks viz., IS 18551, IS 2205, IS 2312 and a susceptible checks i.e. DJ 6514 and Amruta. The shoot fly females lay white, elongated, cigar shaped eggs singly 
on the under surface of the leaves, parallel to midrib in randomly selected row in each plot on 14 and 21 DAE. The data on number of eggs/ plant were calculated for each entry. A usual method to assess the damage caused by shoot fly is to record dead hearts caused by its feeding. The total number of plants and those showing dead hearts were recorded separately on 21 and 28 day after emergence (DAE). The data on per cent shoot fly damage were calculated and subjected to angular transformation and were statistically analysed.

\section{Results and Discussion}

It could be seen from table 1 that there was significant difference between the genotypes in respect of number of eggs laid per plant in November. If we consider the average egg laying on 14 DAE ranged from 0.12 to 0.45 eggs per plant. The minimum number of eggs per plant was recorded on resistant check, IS 2312 (0.12). However it was at par with resistant check, viz., IS 2205 (0.13), IS 18551 (0.14), IS 18360 (0.15), IS 27204 (0.16), IS 29923 (0.18), Swarna (0.19).The maximum number of eggs per plant were recorded in susceptible check, DJ 6514 (0.45), Amruta (0.41). Moderately resistance check was observed in RSSH 18 (0.28), RSSH 50 (0.25).If we consider the average egg laying on 21 DAE ranged from 0.14 to 0.47 eggs per plant. The minimum number of eggs per plant was recorded on resistant check, IS 2312 (0.14). However it was at par with resistant check, viz., IS 2205 (0.16), IS 18551 (0.15), IS 18360 (0.17), IS 27204 (0.21), IS 29923 (0.21), Swarna (0.20). The maximum number of eggs per plant were recorded in susceptible check, DJ 6514 (0.47), Amruta (0.43). Moderately resistant check was observed in RSSH 18 (0.31), RSSH 50 (0.28). The results of egg laying indicated that non-preference for oviposition may be one of the mechanisms for varietal resistance shoot fly. Similar results were observed by various workers viz., Teli et al., (1983), Singh et al., (1989), Deshpande et al., (2003), Balikai and Birdar (2004). It is seen from table 2 that data on dead hearts in relation to different sowing and genotypes recorded on 21 and 28 DAE were statistically significant.

Table.1 Egg laying of shoot fly on different genotypes of sorghum on $14^{\text {th }}$ DAE and $21^{\text {st }}$ DAE

\begin{tabular}{|c|c|c|}
\hline \multirow{2}{*}{ Genotype } & \multicolumn{2}{|c|}{ Average number of eggs per plant on } \\
\cline { 2 - 3 } & $\mathbf{1 4}^{\text {th }} \mathbf{D A E}$ & $\mathbf{2 1}^{\text {st }} \mathbf{D A E}$ \\
\hline IS 29923 & $0.18(0.82)^{*}$ & $0.21(0.84)$ \\
\hline IS 18360 & $0.15(0.81)$ & $0.17(0.82)$ \\
\hline IS 27204 & $0.16(0.81)$ & $0.21(0.82)$ \\
\hline IS 18551(RC) & $0.14(0.80)$ & $0.15(0.81)$ \\
\hline IS 2205 (RC) & $0.13(0.79)$ & $0.16(0.81)$ \\
\hline IS 2312 (RC) & $0.12(0.79)$ & $0.14(0.80)$ \\
\hline RSSH 18 & $0.28(0.88)$ & $0.31(0.90)$ \\
\hline RSSH 50 & $0.25(0.87)$ & $0.28(0.89)$ \\
\hline Swarna & $0.19(0.83)$ & $0.20(0.84)$ \\
\hline DJ 6514 (SC) & $0.45(0.97)$ & $0.47(0.98)$ \\
\hline Amruta (SC) & $0.41(0.95)$ & $0.43(0.96)$ \\
\hline S.E.土 & 0.0062 & 0.0078 \\
\hline C.D. at 5\% & 0.0182 & 0.0231 \\
\hline
\end{tabular}

* Figures in parentheses are square root transformed values

DAE: Day after emergence, RC: Resistance check, SC: Susceptible check 
Table.2 Shoot fly damage as indicated by dead hearts in different genotypes of sorghum on $21^{\text {st }}$ DAE and $28^{\text {th }}$ DAE

\begin{tabular}{|c|c|c|}
\hline \multirow{2}{*}{ Genotype } & \multicolumn{2}{|c|}{ Average per cent dead hearts on } \\
\cline { 2 - 3 } & $\mathbf{2 1}^{\text {st }} \mathbf{D A E}$ & $\mathbf{2 8}^{\text {th }} \mathbf{D A E}$ \\
\hline IS 29923 & $6.87(15.20)^{*}$ & $9.64(18.09)$ \\
\hline IS 18360 & $6.32(14.5)$ & $9.37(17.82)$ \\
\hline IS 27204 & $6.24(14.47)$ & $9.53(17.98)$ \\
\hline IS 18551 (RC) & $6.03(14.21)$ & $9.10(17.56)$ \\
\hline IS 2205 (RC) & $6.21(14.43)$ & $9.28(17.74)$ \\
\hline IS 2312 (RC) & $5.27(13.27)$ & $7.94(16.37)$ \\
\hline RSSH 18 & $10.54(18.94)$ & $14.68(22.53)$ \\
\hline RSSH 50 & $9.70(18.15)$ & $13.21(21.30)$ \\
\hline Swarna & $7.90(16.32)$ & $11.08(19.44)$ \\
\hline DJ 6514 (SC) & $17.78(24.94)$ & $25.89(25.89)$ \\
\hline Amruta (SC) & $15.19(22.94)$ & $24.98(24.98)$ \\
\hline S.E.土 & 0.1661 & 0.2882 \\
\hline C.D. at 5\% & 0.4899 & 0.8502 \\
\hline
\end{tabular}

* Figures in parentheses are arcsin transformed values

DAE: Day after emergence, RC: Resistant check, SC: Susceptible check

If we consider the average per cent dead hearts on 21 DAE ranged from 5.27 to 17.78. The minimum number of average per cent dead hearts was recorded in resistant check, IS 2312 (5.27). However entries IS 18360 (6.32), IS 27204 (6.24) and IS 2205 (6.21) were at par. Average percent dead hearts in genotypes were viz., IS 29923 (6.87), IS 18551 (6.03) and Swarna (7.90). The maximum number average per cent dead hearts were recorded in susceptible check, DJ 6514 (17.78), Amruta (15.19) and in moderately resistant check, RSSH 18 (10.54) and RSSH 50 (9.70).If we consider the average per cent dead hearts on 28 DAE ranged from 7.94 to 25.89 .

The minimum number of average per cent dead hearts was recorded in resistant check, IS 2312 (7.94). However entries IS 18360 (9.37) and IS 27204 (9.53) were at par. Average percent dead hearts in genotypes were viz., IS 29923 (9.64), IS 18551 (9.10), IS 2205 (9.28) and Swarna (11.08). The maximum number average per cent dead hearts were recorded in susceptible check, DJ 6514 (25.89), Amruta (24.98) and in moderately resistant check, RSSH 18 (14.68) and RSSH 50 (13.21).

This varied reaction of different entries was mainly associated with egg laying indicating ovipositional non-preference as a primary mechanism of shoot fly resistance. The similar, observation were recorded by various workers viz., Sawang et al., (1988), Balikai et al., (1999), Balikai and Biradar (2004).

\section{References}

Balikai, R.A., and Biradar, B.D. 2004. Performance of sorghum germplasm lines against shoot fly in rabi sorghum. Agric. Sci. Digest, 24(1): 63-64.

Balikai, R.A., and Kullaiswamy, B.Y. 1999. Evaluation of F2 populations and their parents for resistance to sorghum shoot fly, Atherigona soccata (Rondani). Insect Environ, 5(2): 54-55.

Deshpande, V.P., Kamatar, M.Y., Kathnalli, 
D.S., Malleshappa, S.M. and Nayakar, N.Y. 2003. Screening of sorghum genotypes against shoot fly, Atherigona soccata (Rondani). Indian J.Pl. Prot., 31 (1): 90-93.

Dhillon, M.K., Sharma H.C., and B.V.S. Reddy. 2005b. Agronomic characteristics of different cytoplasmic male sterility system and their reaction to the sorghum shoot fly, Atherigona soccata. ISMN, 46:52-55.

Dhillon, M.K., Sharma H.C., Reddy B.V.S., Ram Singh, Naresh J.S. and Zhu Kai. 2005a. Relative susceptibility of different male-sterility cytoplasms in sorghum to shoot fly, Atherigona soccata. Euphytica, 144: 275-283.

F. A. O. 2011. FAOSTAT, http: // faostat.fao.org

Sawang, Charoenying, Somchai, Isichaikul, Weerawan and Amornsak. 1988.
Screening of sorghum varieties for resistance to the sorghum shoot fly, Atherigona soccata Rond. (Muscidae: Diptera) under field conditions.

Sharma, H.C., and Nwanze, K.F. 1997. Mechanism of resistance to insect in sorghum and their usefulness in crop improvement. Information Bulletine No. 45. International Crop Research Institute for the Semi-Arid Tropics, Patancheru, pp-56.

Singh, Y.P., Singh, AK, Singh, B. and Pandey, N.D. 1989. Susceptibility of sorghum germplasm to Atherigona soccata Rondani. Farm Sci. J., 4(1,2): 28-31.

Teli, V.S., M.B. Pawar and S.E. Kalbhor.1983. Relative susceptibility of some varieties and hybrids of sorghum to shoot fly. J. Maharashtra Agric. Univer., 8(3): 217-218.

\section{How to cite this article:}

Patil, S.P. and Bagde, A.S. 2017. Screening of Advanced Breeding Material of Sorghum against Shoot Fly (Atherigona soccata) (Rondani). Int.J.Curr.Microbiol.App.Sci. 6(9): 27472750. doi: https://doi.org/10.20546/ijcmas.2017.609.338 